\title{
Matrix Metalloproteinase-2 and -7 Expression in Colorectal Cancer
}

\author{
Seong Woo Hong, Yun Kyung Kang ${ }^{1}$, Byungmo Lee, Woo Yong Lee, Yeo Gu Jang, In Wook Paik, \\ Hyucksang Lee \\ Departments of Surgery and ${ }^{1}$ Pathology, Seoul Paik Hospital, Inje University College of Medicine, Seoul, Korea
}

Purpose: Matrix metalloproteinase-2 (MMP-2) and MMP-7 have been implicated in tumor growth and metastasis. This study aimed to investigate the expressions of MMP-2 and -7 in colorectal cancer and to evaluate their values as prognostic markers. Methods: Immunohistochemical staining for MMP-2 and -7 was done in 144 resected colorectal cancer specimens. Clinicopathological data and survival results were compared with regard to the expression results.

Results: The expression rates of MMP-2 in tumor cells in the tumor center and the tumor border were $16.7 \%$ and $38.9 \%$, respectively. That of MMP-2 in stromal cells was 27.8\%. MMP-7 immunoreactivities of tumor cells in the tumor center and the tumor border were $6.9 \%$ and $23.6 \%$. The expressions of MMP-2 and MMP-7 were correlated. MMP-2 expression in stromal cells was more increased in the distal part of the colorectum: $8.8 \%$ in right colon cancer, $29.5 \%$ in left colon cancer and $36.4 \%$ in rectal cancer. MMP-2 expression of tumor cells in the tumor border was correlated with T-stage. MMP-7 expression of tumor cells in the tumor border was increased in case of infiltrative cancer compared with fungating tumor. The expression patterns of MMP-2 and -7 were not correlated with other clinicopathological factors, including tumor markers, node metastasis, distant metastasis, lymphatic invasion, tumor differentiation, and recurrence. No significant associations between the overall and disease-free survival rates and the MMP-2 and -7 expression patterns were noted.

Conclusion: The high expression rates of MMP-2 and -7 in tumor borders suggest that MMP-2 and - 7 have some role in tumor invasion, but in this study, MMP-2 and -7 did not appear to be significant predictors of prognosis in colorectal cancer.

Keywords: Matrix metalloproteinases; Colorectal neoplasms; Prognosis; Immunohistochemistry

\section{INTRODUCTION}

Matrix metalloproteinases (MMPs) are enzymes that degrade extracellular matrices. These enzymes mediate not only normal physiological functions, such as tissue remodeling and development of organs, they also play a role in pathologic condition, such as regulation of inflammatory reactions, tumor growth and metastasis [1]. The roles of MMP in cancer growth and metastasis are related to their degradation of extracellular matrices, pertinent to cell adhe-

Received: January 24, 2011 Accepted: June 14, 2011

Correspondence to: Seong Woo Hong, M.D.

Department of Surgery, Seoul Paik Hospital, Inje University College of

Medicine, 85 Jeo-dong 2-ga, Jung-gu, Seoul 100-032, Korea

Tel: +82-2-2270-0016, Fax: 82-2-2270-0373

E-mail:cosmo021@hanmail.net

(C) 2011 The Korean Society of Coloproctology

This is an open-access article distributed under the terms of the Creative Commons Attribution NonCommercial License (http://creativecommons.org/licenses/by-nc/3.0) which permits unrestricted noncommercial use, distribution, and reproduction in any medium, provided the original work is properly cited. sion and migration, and secretion of growth factors, cytokines, vascular growth factors. Studies on MMP have been conducted in breast cancer, pancreatic cancer, lung cancer, colorectal cancer, ovarian cancer, prostate cancer, and brain cancer, and based on those studies, cancer treatment that apply MMP suppressors have been attempted [2].

According to the 2008 Korean survey, colorectal cancer is the 4th leading cause of death (9.9\%) among all cancers, and recently, it has shown an increasing trend in Korea [3]. The prognosis for colorectal cancer is relatively good. Nonetheless, the 5-year survival rate of TNM stage III cancer with lymph node metastasis is merely $25-60 \%$. In this stage, postoperative adjuvant chemotherapy has been reported to improve the prognoses for patients; however, many patients die due to recurrence and metastasis of the cancer. In stage II cancer without lymph node metastasis, the effect of chemotherapy is not clear yet [4]. In colorectal cancer, the most important prognostic factor is, of course, the stage of tumor. Nevertheless, it is important to find new prognostic factors as a basis for determining the prognoses for patients, follow-ups, and post- 
surgical treatments. MMPs have been investigated in regard to tumor growth and metastasis, and in colorectal cancer, they have been reported to play an important role in the development and growth of tumors and in the metastasis process [5]. However, the results of studies that examined whether MMPs were significant prognostic factors in colorectal cancer are contradictory in many cases [2]. The authors examined the expressions of MMP-2 and MMP-7 in colorectal cancer, and their significance as prognostic factors was examined by investigating the expression characteristics, the association with other pathological findings, and the association with the prognoses for patients.

\section{METHODS}

\section{Subjects}

The study was conducted on 144 patients who were diagnosed as having as colorectal adenocarcinoma and who underwent a resection from January 1998 to August 2004.

\section{Clinicopathological factors}

Based on clinical records and pathology reports, the location of the tumor, serum CEA, T-stage, lymph node metastasis, distant metastasis, pathological differentiation grade, lymphatic invasion, macroscopic morphology of tumor, and recurrence were examined. Based on the splenic flexure, the area of the colon was classified based as the right colon or the left colon. The upper border of the rectum was defined as being $15 \mathrm{~cm}$ away from the anal verge. For the prognoses for patients, we analyzed the overall survival rate and the disease-free survival rate. Follow-up observations were performed until December 2009, and the average follow-up observation period was 61.8 months (range, 2 to 133 months). Survivals were assessed based on clinical records and telephone interviews.

\section{Immunohistochemical staining methods}

Tissue arrays were prepared by consigning them to the SuperBioChips, Co. (Seoul, Korea). Tissue array blocks were sectioned with 4- $\mu \mathrm{m}$ thicknesses, and immunohistochemical staining was performed. Paraffin was removed, and to suppress endogenous peroxidase, the samples were treated with $0.3 \%$ hydrogen peroxide. The samples were reacted with primary anti-MMP-2 antibody (clone A-Gel VC2, 1:400 dilution; Neomarkers, Fremont, CA, USA) or primary anti-MMP-7 antibody (clone ID-2, 1:1,500 dilution; Chemicon, Temecula, CA, USA) at room temperature for 1 hour, washed with phosphate-buffered saline, reacted with biotynylated secondary antibody, and incubated with avidin-biotin streptavidin-peroxidase complex (Vectastatin Elite ABC kit; Vector Laboratories, Burlingame, CA, USA). As dyes, 3,3'-diaminobenzidine tetrahydrochloride was used, and counter staining was done with Mayer's hemotoxylin. The negative control group was stained by using the identical procedure, but omitting the first antibody. Immunohistochemical staining of the specimens was evaluated by one pathologist (a co-author). The criterion for a positive expression was more than $10 \%$ of the cytoplasm showing a distinct expression higher than moderate levels. In regard to MMP-2, the expressions in the central and the border areas of the tumors and in the interstitium around stumor cells were examined. In regard to MMP-7, only the expressions in the centers of tumor cells and in the border areas of the tumors were examined. MMP-2 has been reported to be primarily produced by interstitial tissues and MMP-7 to be primarily produced and expressed by epithelial cells [6]. In the preliminary experiments of our study, no expression of MMP-7 in the interstitium was observed; thus, the expression of MMP-7 in the interstitium was not examined.

\section{Statistical analysis methods}

For the comparison of categorical data, the chi-square test was applied. Survival rates were obtained by using the Kaplan-Meier method and were compared by using the Log-Rank method. Statistical significance was associated with a $\mathrm{P}<0.05$.

\section{RESULTS}

\section{Expressions of MMP-2 and MMP -7 and their correlation}

MMP-2 was expressed in the central area of the tumor in 24 cases (16.7\%), in the border area in 56 cases (38.9\%), and in the interstitium in 40 cases $(27.8 \%)$. MMP-7 was expressed in the central area of the tumor in 10 cases (6.9\%) and in the border area in 34 cases (23.6\%) (Fig. 1, Table 1). The expression of MMP-2 in the central area correlated significantly to the expression MMP-2 in the border area $(\mathrm{P}<0.001)$ and to the expression of MMP-7 in the central area $(\mathrm{P}=0.04)$. The expression of MMP-2 in the border area correlated significantly to the expression of MMP-2 in interstitial tissues ( $\mathrm{P}=0.001$ ), the expression of MMP-2 in interstitial tissues significantly correlated to the expression of MMP-7 in the border area $(\mathrm{P}=0.004)$, and the expression of MMP-7 in the central area correlated significantly to the expression of MMP-7 in the border area $(\mathrm{P}=0.005)$ (Table 2$)$.

\section{Comparison of the expressions of MMP with clinicopathological factors}

When expressions of MMP were compared with clinicopathological factors, positive expressions of MMP-2 in the border areas in the right colon, the left colon, and the rectum were observed in 8 out of 34 patients $(23.5 \%)$, in 18 out of 44 patients (40.9\%), and in 30 out of 66 patients (45.5\%), respectively. A trend was noted in

Table 1. Expressions of MMP-2 and -7 in tumors and stromas

\begin{tabular}{lllc}
\hline & Tumor center & Tumor border & Stroma \\
\hline MMP-2 expression & $24 / 144(16.7)$ & $56 / 144(38.9)$ & $40 / 144(27.8)$ \\
MMP-7 expression & $10 / 144(6.9)$ & $34 / 144(3.6)$ & Not done \\
\hline
\end{tabular}

Values are presented as no./no. of total (\%).

MMP, matrix metalloproteinase. 

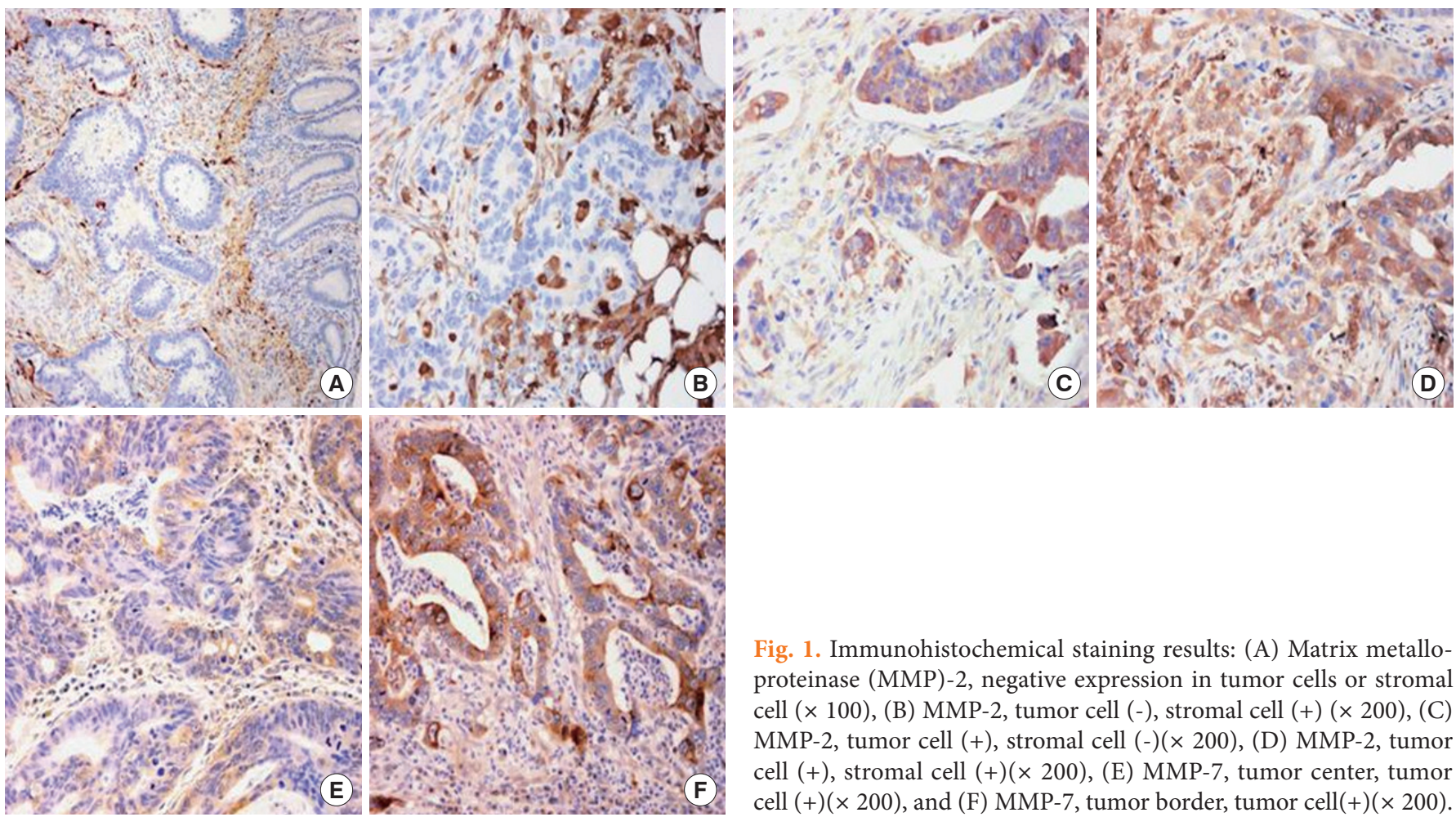

Table 2. Relationship of MMP-2 and MMP-7 expressions in different areas

\begin{tabular}{|c|c|c|c|c|}
\hline & $\begin{array}{c}\text { MMP-2 } \\
\text { border }\end{array}$ & $\begin{array}{l}\text { MMP-2 } \\
\text { stroma }\end{array}$ & $\begin{array}{l}\text { MMP-7 } \\
\text { center }\end{array}$ & $\begin{array}{l}\text { MMP-7 } \\
\text { border }\end{array}$ \\
\hline MMP-2 center ${ }^{\mathrm{a}}$ & $<0.001$ & 0.405 & 0.040 & 0.160 \\
\hline MMP-2 border $^{\mathrm{b}}$ & & 0.001 & 0.156 & 0.128 \\
\hline MMP-2 stroma ${ }^{\mathrm{C}}$ & & & 0.104 & 0.004 \\
\hline MMP-7 center $^{d}$ & & & & 0.005 \\
\hline
\end{tabular}

Values are presented as P-values.

MMP, matrix metalloproteinase.

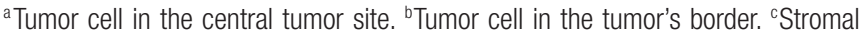
cell adjacent to a tumor cell. ${ }^{\mathrm{d}}$ Tumor cell in the central tumor site.

that MMP-2 was expressed more toward the distal bowel $(\mathrm{P}=$ $0.098)$. The expression according to $\mathrm{T}$ stage was $11.1 \%$ in $\mathrm{T} 1(1 / 9)$, $33.3 \%$ in T2 (5/15), $46.2 \%$ in T3 (49/106), and 7.1\% in T4 (1/14) $(\mathrm{P}=0.001)$. Concerning the expression of MMP-2 in interstitial tissues, the positive rate for the right colon was $8.8 \%(3 / 34)$, that for the left colon was $29.5 \%(13 / 44)$, and that for the rectum was $36.4 \%(24 / 66)$. Expression was clearly higher toward the distal bowel $(\mathrm{P}=0.014)$. MMP-7 was expressed in the border area of the tumor in 21 out of 109 fungating tumor cases (19.3\%), and in infiltrative cases, it was expressed in 13 out of 35 cases (37.1\%) $(\mathrm{P}=$ 0.04). Tumor markers, lymph node metastasis, distant metastasis, tumor differentiation grade, lymphatic duct invasion, and recurrence were examined. Nevertheless, factors that correlated to the

Fig. 1. Immunohistochemical staining results: (A) Matrix metalloproteinase (MMP)-2, negative expression in tumor cells or stromal cell (× 100), (B) MMP-2, tumor cell (-), stromal cell $(+)(\times 200),(C)$ MMP-2, tumor cell (+), stromal cell (-) ( $\times 200)$, (D) MMP-2, tumor cell $(+)$, stromal cell $(+)(\times 200),($ E) MMP-7, tumor center, tumor cell $(+)(\times 200)$, and $($ F) MMP-7, tumor border, tumor cell $(+)(\times 200)$.

expression of MMP were not found (Table 3). The association of the expression of MMP-2 or MMP-7 in the central area of the tumor with clinicopathological factors was also examined, but no statistically significance differences were found.

\section{Expressions of MMP-2 and MMP-7 and the prognosis for the patient}

Among 144 patients, in the 136 patients who underwent curative resection, the overall survival rate and the disease-free survival rate according to the expressions of MMP-2 and MMP-7 were examined. The 5-year survival rate of the patients with positive expression of MMP-2 in the border area was 75.3\%, and that of patients with negative expression was $73.6 \%(\mathrm{P}=0.7955)$ (Fig. 2). The 5year survival rate of patients with positive MMP-2 expression in interstitial tissues was $75.2 \%$, and that of patients with negative expression was $74.0 \%(\mathrm{P}=0.7340)$ (Fig. 3$)$. The 5 -year survival rate of patients with positive MMP-7 expression in the border area was $79.9 \%$, and that of patients with negative expression was $72.8 \%(\mathrm{P}=$ 0.5175 ) (Fig. 4). The 5-year disease free survival rates of patients with positive and negative expressions of MMP-2 in the border area were $68.4 \%$ and $70.3 \%(\mathrm{P}=0.8290)$, respectively. The 5 - year disease-free survival rates for patients with positive and negative expressions of MMP-2 in interstitial tissues were $65.3 \%$ and $71.1 \%$ $(\mathrm{P}=0.8171)$, respectively. The 5 -year disease-free survival rates of patients with positive and negative expressions of MMP-7 in the border area were $66.1 \%$ and $70.5 \%$, respectively, but this difference was not statistically significant $(P=0.7682)$. The association of the 
Table 3. Relationship between the expression of MMP and the clinicopathological factors

\begin{tabular}{|c|c|c|c|c|c|c|}
\hline & MMP-2 border ${ }^{\mathrm{a}}$ & P-value & MMP-2 stroma ${ }^{b}$ & P-value & MMP-7 border ${ }^{\mathrm{C}}$ & P-value \\
\hline \multicolumn{7}{|l|}{ Tumor location } \\
\hline Right colon & $8 / 34$ & 0.098 & $3 / 34$ & 0.014 & $8 / 34$ & 0.546 \\
\hline Left colon & $18 / 44$ & & $13 / 44$ & & $8 / 44$ & \\
\hline Rectum & $30 / 66$ & & $24 / 66$ & & $18 / 66$ & \\
\hline \multicolumn{7}{|l|}{ CEA (ng/mL) } \\
\hline$>5$ & $12 / 35$ & 0.599 & $13 / 35$ & 0.174 & $8 / 35$ & 0.951 \\
\hline$\leq 5$ & $42 / 107$ & & $27 / 107$ & & $25 / 107$ & \\
\hline \multicolumn{7}{|l|}{ T stage } \\
\hline $\mathrm{T} 1$ & $1 / 9$ & 0.010 & $2 / 9$ & 0.758 & $2 / 9$ & 0.958 \\
\hline T2 & $5 / 15$ & & $3 / 15$ & & $3 / 15$ & \\
\hline T3 & $49 / 106$ & & $32 / 106$ & & $25 / 106$ & \\
\hline T4 & $1 / 14$ & & $3 / 14$ & & $4 / 14$ & \\
\hline \multicolumn{7}{|l|}{ Node metastasis } \\
\hline Present & $29 / 73$ & 0.344 & $22 / 73$ & 0.522 & $21 / 73$ & 0.140 \\
\hline Absent & $27 / 71$ & & $18 / 71$ & & $13 / 71$ & \\
\hline \multicolumn{7}{|l|}{ Distant metastasis } \\
\hline Present & $3 / 12$ & 0.303 & $2 / 12$ & 0.369 & $4 / 12$ & 0.408 \\
\hline Absent & $53 / 132$ & & $38 / 132$ & & $30 / 132$ & \\
\hline \multicolumn{7}{|l|}{ Differentiation } \\
\hline Well to moderately & $47 / 125$ & 0.416 & $35 / 125$ & 0.879 & $27 / 125$ & 0.145 \\
\hline Poorly & $9 / 19$ & & $5 / 19$ & & $7 / 19$ & \\
\hline \multicolumn{7}{|l|}{ Lymphatic invasion } \\
\hline Positive & $49 / 125$ & 0.844 & $35 / 125$ & 0.879 & $32 / 125$ & 0.149 \\
\hline Negative & $7 / 19$ & & $5 / 19$ & & $2 / 19$ & \\
\hline \multicolumn{7}{|c|}{ Gross findings of the tumor } \\
\hline Fungating & $41 / 109$ & 0.580 & $31 / 109$ & 0.754 & $21 / 109$ & 0.040 \\
\hline Infiltrating & $15 / 35$ & & $9 / 35$ & & $13 / 35$ & \\
\hline \multicolumn{7}{|l|}{ Recurrences } \\
\hline Present & $18 / 42$ & 0.546 & $13 / 42$ & 0.407 & $12 / 42$ & 0.329 \\
\hline Absent & $34 / 91$ & & 22/91 & & $19 / 91$ & \\
\hline
\end{tabular}

MMP, matrix metalloproteinase; CEA, carcinoembryonic antigen.

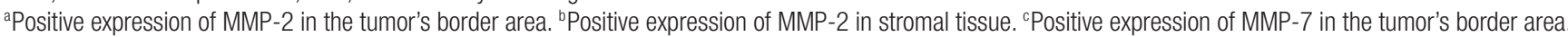

expressions of MMP-2 or MMP-7 in the central area of the tumor with prognosis was examined, but no significant result was found.

\section{DISCUSSION}

MMPs are kinds of enzymes that degrade extracellular matrices, and they act under both normal physiologic and pathologic conditions. Twenty-four types of MMPs, including 5 types of secreted MMPs and 3 types of membrane bound MT-MMPs, have been reported. In regard to tumors, most MMPS are produced and secreted by interstitial tissues in the vicinity of the tumor in response to the stimulation of tumor cells [7]. Until recently, MMPs have been reported to exert effects on the process of tumor invasion and metastasis. Recently, they have also been reported to play an important role in the early development of tumors [8].

In regard to the early oncogenic process of colorectal cancer, primarily MMP-7 has been investigated. In a study that examined the expression of MMP-7 in dysplasia that developed in ulcerative colitis, in low-grade dysplasia, it was shown to be expressed less, and in high-grade dysplasia and cancer, the expression of MMP-7 was clearly shown, thus establishing that MMP-7 played a role in the early phase of cancer development [9]. In addition, in a study con- 


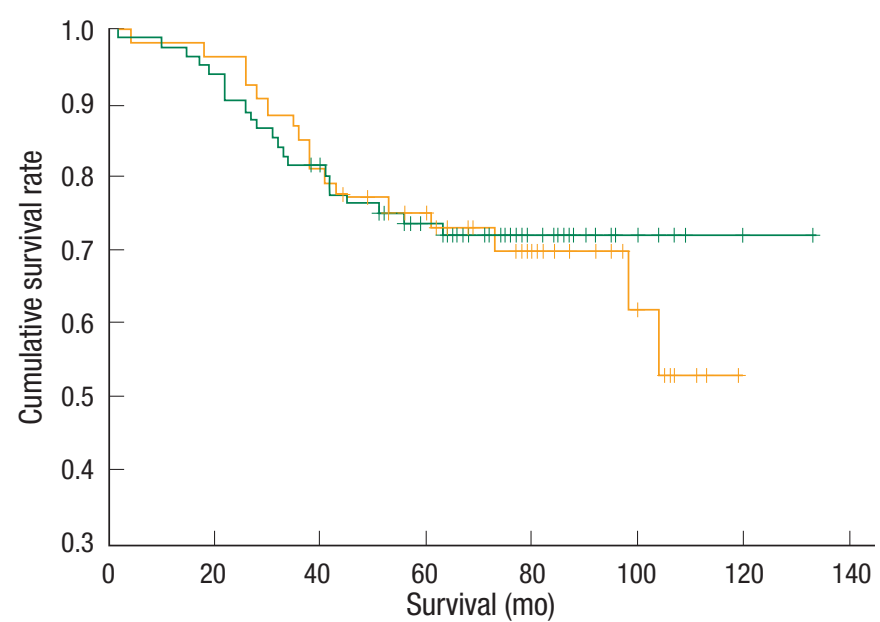

Fig. 2. Survival curve according to matrix metalloproteinase (MMP)-2 expression on the tumor's border: solid line (negative expression of MMP-2) and broken line (positive expression of MMP-2).

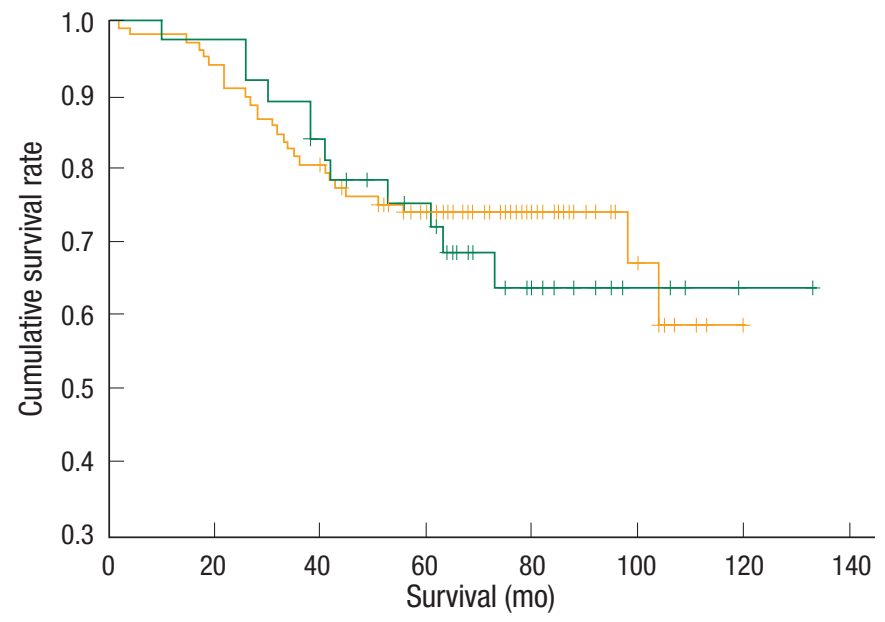

Fig. 3. Survival curve according to matrix metalloproteinase (MMP)-2 expression on a stromal cell: solid line (negative expression of MMP2) and broken line (positive expression of MMP-2).

ducted on liver metastasis of colorectal cancer, Zeng et al. [10] examined the expression of MMP-7 and observed that MMP-7 mRNA and enzyme activity were over-expressed in metastatic cancer tissues in comparison with normal liver tissues, and in immunohistochemical staining, the border area of the cancer showed strong expression of MMP-7; thus, MMP-7 played an important role in liver metastasis of colorectal cancer.

Some investigations of the association of MMP-2 expression with distant metastasis of colorectal cancer have been performed. Brand et al. [11] reported a significant reduction of liver metastasis in animal experiments using the gene of the MMP-2 suppressor, the tissue inhibitor of MMP-2 (TIMP-2). In patients with the elevated levels of plasma MMP-2, lymph node metastasis has been reported to occur more frequently [12].

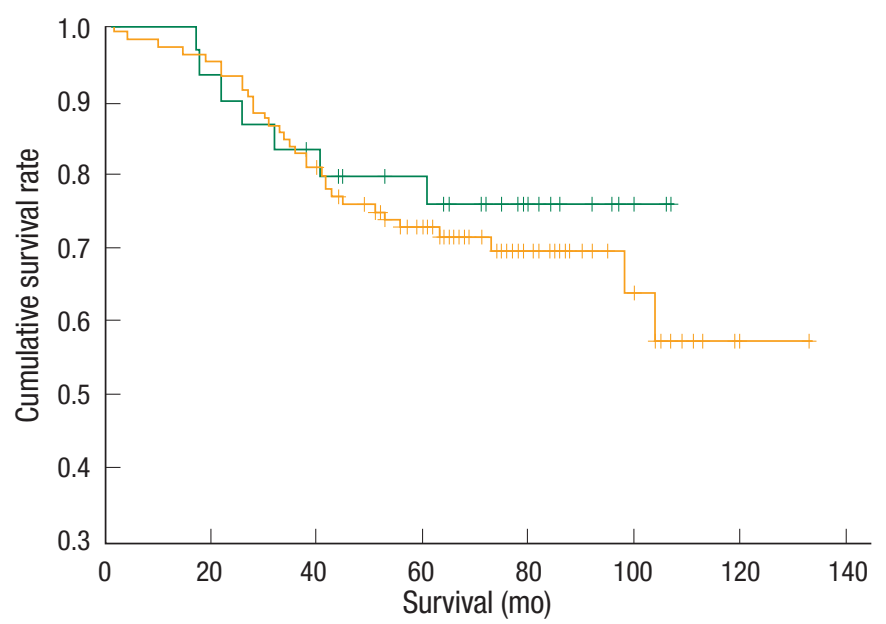

Fig. 4. Survival curve according to matrix metalloproteinase (MMP)-7 expression on the tumor's border: solid line (negative expression of MMP-7) and broken line (positive expression of MMP-7).

In our study, the expression of MMP-2 in tumor tissues and interstitial tissues, as well as the expression of MMP-7 in tumor tissues, were examined by immunohistochemical staining. Others have reported that MMP-7 is produced by epithelial cells and that it is not expressed in the interstitium $[6,13]$. In our preliminary experiments, MMP-7 was not expressed in the interstitium. MMP-2 was expressed in the central areas of the tumors in $16.7 \%$ of the cases, and in the border areas in $38.8 \%$ of the cases. MMP-7 was expressed in the central areas of tumors in $6.9 \%$ of the cases, and in the border areas in $23.6 \%$ of the cases. This is in agreement with the results of most studies that examined the expressions of MMP-2 and MMP-7 by immunohistochemical staining; i.e., MMP was strongly expressed in the borders of the tumors, in other ward, in cancer cells in the front lines of cancers that invade normal tissues [10, 13-16].

Previous studies have reported that MMP- 2 is produced primarily by fibroblasts in interstitial tissues and is activated in tumor cells [17] and that during the process, the mutual action of tumor cells and interstitial cells is important [18]; this can be explained by MMP-2 being expressed strongly in the border areas of tumors where tumor and interstitial tissues are abundant. MMP-7 was also observed to be expressed strongly in the border areas of tumors, and similar to MMP-2, this was explained by some investigators as being due to the mutual interaction of tumors and host cells [16]. Such strong expression of MMP in the border area is thought to accelerate the degradation of the tumor matrix and to activate tumor invasion and metastasis.

No studies have reported expressions in the central area and the border area separately as our study has done. Most studies examined and reported the expression of MMP in the border area, and MMP-2 was expressed in 35-87\% of the cases [13-15], and MMP-7 was expressed in $54-84 \%$ of the cases $[13,14,19]$. In our study, the expression rate was low, but the standards for evaluation were dif- 
ferent; thus, objective comparisons are difficult. In our study, the expression of MMP-2 in the border areas of tumors and in the interstitium were $38.9 \%$ and $27.8 \%(\mathrm{P}=0.001)$. This may be explained sufficiently by the mutual relation of tumor cells and interstitial tissues that was described above. In regard to the site of the expression of MMP-2, Schwandner et al. [13] reported that it was expressed in tumor cells in $35 \%$ of the cases and in the interstitium in $77 \%$ of the cases. Hilska et al. [14] reported that MMP-2 expressions in tumor cells and in the interstitium were comparable in $87 \%$ of the cases. Papadopoulou et al. [20] reported that MMP-2 was expressed in tumor cells in $44 \%$ of the cases and in the interstitium in approximately $50 \%$ of the cases. Nonetheless, the staining intensity of the interstitium was weaker than that of tumor cells. Such differences appear to be due to differences in research and assessment methods.

In our study, in the central areas of tumors, the expressions of MMP-2 and MMP-7 correlated ( $\mathrm{P}=0.04)$, and in the interstitium, the expression of MMP-2 was associated with the expression of MMP-7 in tumors in the vicinity $(\mathrm{P}=0.004)$. This is a result that is in agreement with research reports showing that MMP-7 contributes to the activation of pro-MMP-2 [21].

When the expression of MMP is compared with clinicopathological factors, MMP-7 was expressed in the border areas of macroscopic elevated type tumors in $19.3 \%$ of the cases, in invasive type tumors with unclear borders, it was expressed in $37.1 \%$ of the cases $(\mathrm{P}=0.03)$, and in areas where tumor invasion was active, it was found to be expressed well. However, it was not associated with disease stage, tumor differentiation grade, tumor markers, lymphatic duct invasion, distant metastasis, and recurrence. In regard to the expression of MMP-2 in the interstitium, it was expressed in the right colon in $8.8 \%$ of the cases, in the left colon in $29.5 \%$ of the cases, in the rectum in $36.4 \%$ of the cases; toward the distal bowel, it was expressed more $(\mathrm{P}=0.014)$. In the colon, the expression of MMP-2 in interstitial tissues was $20.5 \%$, and in the rectum, it was $36.4 \%$, and that difference was significant $(\mathrm{P}=0.034)$. This is different from the results of other studies in which the expressions of MMP-2 in the colon and the rectum were not different $[22,23]$. Nevertheless, because of the different study methods, the results are difficult to compare. However, MMP-2 is produced mainly in the interstitium [24]; thus more significant results may be obtained by assessing the expression in the interstitium. The expression of MMP-2 did not correlate to the prognostic factors of colorectal cancer patients, such as tumor stage, tumor cell differentiation grade, tumor markers, lymphatic duct invasion, distant metastasis, and recurrence.

In our study, the prognoses of patients based on the expressions of MMP-2 and MMP-7 were not different. Concerning this point, many studies have reported contradictory results. Cho et al. [25] reported that MMP-2 was not associated with several clinicopathological factors that show tumor invasiveness. Schwandner et al. [13] also reported that in rectal cancer, MMP-2 and MMP-7 expressions were not associated with prognosis. On the other hand,
Hilska et al. [14] reported that the prognosis of colon cancer patients with the expression of MMP-2 was poor. Sundov et al. [15] reported that in disease stage Duke's B colon cancer patients, the expression of MMP-2 was a poor prognostic factor. Adachi et al. [16] reported that the expression of MMP-7 was an independent prognostic factor in patients with colorectal cancer. By measuring the serum MMP-7 of patients, Maurel et al. [26] observed that it was elevated in cases of advanced colorectal cancer, and that it was an independent prognostic factor. Because of such varying reports, it appears to be difficult to answer definitely the question of whether a specific MMP is a significant prognostic factor. As neovascularization of a tumor is achieved by the coordination of its stimulating factors and antagonistic factors, the action of MMP, which is associated with tumor invasion and metastasis, must be understood within its relationship with the inhibitory factors that areTIMP [27].

In colorectal cancer, MMP-2 and MMP-7 were expressed more strongly in the border areas of tumors than in the central areas. In our study, the expressions of MMP-2 or MMP-7 did not significantly correlate to an advanced level of cancer; similarly, it had no correlation with the prognoses for patients.

\section{CONFLICT OF INTEREST}

No potential conflict of interest relevant to this article was reported.

\section{ACKNOWLEDGMENTS}

This work was supported by Inje University, a grant of 2008. This article was poster presented at the Korean Surgical Society 62nd Symposium in 2010.

\section{REFERENCES}

1. Kessenbrock K, Plaks V, Werb Z. Matrix metalloproteinases: regulators of the tumor microenvironment. Cell 2010;141:52-67.

2. Roy R, Yang J, Moses MA. Matrix metalloproteinases as novel biomarkers and potential therapeutic targets in human cancer. J Clin Oncol 2009;27:5287-97.

3. National Cancer Information Center. Cancer incidence rate 2008 [Internet]. Goyang: National Cancer Information Center; c2008 [cited 2011 June 1]. Available from: http://www.cancer.go.kr/cms/ statics/incidence/index.html.

4. Wolpin BM, Meyerhardt JA, Mamon HJ, Mayer RJ. Adjuvant treatment of colorectal cancer. CA Cancer J Clin 2007;57:168-85.

5. Sun XF, Zhang H. Clinicopathological significance of stromal variables: angiogenesis, lymphangiogenesis, inflammatory infiltration, MMP and PINCH in colorectal carcinomas. Mol Cancer 2006;5:43.

6. Leeman MF, Curran S, Murray GI. New insights into the roles of matrix metalloproteinases in colorectal cancer development and progression. J Pathol 2003;201:528-34.

7. van der Jagt MF, Wobbes T, Strobbe LJ, Sweep FC, Span PN. Metalloproteinases and their regulators in colorectal cancer. J Surg 
Oncol 2010;101:259-69.

8. Stamenkovic I. Extracellular matrix remodelling: the role of matrix metalloproteinases. J Pathol 2003;200:448-64.

9. Newell KJ, Matrisian LM, Driman DK. Matrilysin (matrix metalloproteinase-7) expression in ulcerative colitis-related tumorigenesis. Mol Carcinog 2002;34:59-63.

10. Zeng ZS, Shu WP, Cohen AM, Guillem JG. Matrix metalloproteinase-7 expression in colorectal cancer liver metastases: evidence for involvement of MMP-7 activation in human cancer metastases. Clin Cancer Res 2002;8:144-8.

11. Brand K, Baker AH, Perez-Cantó A, Possling A, Sacharjat M, Geheeb $\mathrm{M}$, et al. Treatment of colorectal liver metastases by adenoviral transfer of tissue inhibitor of metalloproteinases- 2 into the liver tissue. Cancer Res 2000;60:5723-30.

12. Langenskiold M, Holmdahl L, Falk P, Ivarsson ML. Increased plasma MMP-2 protein expression in lymph node-positive patients with colorectal cancer. Int J Colorectal Dis 2005;20:245-52.

13. Schwandner O, Schlamp A, Broll R, Bruch HP. Clinicopathologic and prognostic significance of matrix metalloproteinases in rectal cancer. Int J Colorectal Dis 2007;22:127-36.

14. Hilska M, Roberts PJ, Collan YU, Laine VJ, Kossi J, Hirsimäki P, et al. Prognostic significance of matrix metalloproteinases-1, -2, -7 and -13 and tissue inhibitors of metalloproteinases- $1,-2,-3$ and -4 in colorectal cancer. Int J Cancer 2007;121:714-23.

15. Sundov Z, Tomić S, Vilović K, Kunac N, Kalebić M, Bezić J. Immunohistochemically detected high expression of matrix metalloproteinase-2 as predictor of poor prognosis in Duke's B colon cancer. Croat Med J 2008;49:636-42.

16. Adachi Y, Yamamoto H, Itoh F, Arimura Y, Nishi M, Endo T, et al. Clinicopathologic and prognostic significance of matrilysin expression at the invasive front in human colorectal cancers. Int J Cancer 2001;95:290-4.

17. Ko K, Yazumi S, Yoshikawa K, Konda Y, Nakajima M, Chiba T, et al. Activation of fibroblast-derived matrix metalloproteinase- 2 by colon-cancer cells in non-contact Co-cultures. Int J Cancer 2000; 87:165-71.

18. Ornstein DL, MacNab J, Cohn KH. Evidence for tumor-host co- operation in regulating MMP-2 expression in human colon cancer. Clin Exp Metastasis 1999;17:205-12.

19. Wang WS, Chen PM, Wang HS, Liang WY, Su Y. Matrix metalloproteinase-7 increases resistance to Fas-mediated apoptosis and is a poor prognostic factor of patients with colorectal carcinoma. Carcinogenesis 2006;27:1113-20.

20. Papadopoulou S, Scorilas A, Arnogianaki N, Papapanayiotou B, Tzimogiani A, Agnantis N, et al. Expression of gelatinase-A (MMP2 ) in human colon cancer and normal colon mucosa. Tumour Biol 2001;22:383-9.

21. Wang FQ, So J, Reierstad S, Fishman DA. Matrilysin (MMP-7) promotes invasion of ovarian cancer cells by activation of progelatinase. Int J Cancer 2005;114:19-31.

22. Li M, Li JY, Zhao AL, Gu J. Colorectal cancer or colon and rectal cancer? Clinicopathological comparison between colonic and rectal carcinomas. Oncology 2007;73:52-7.

23. Kim TD, Song KS, Li G, Choi H, Park HD, Lim K, et al. Activity and expression of urokinase-type plasminogen activator and matrix metalloproteinases in human colorectal cancer. BMC Cancer 2006;6:211.

24. Taniwaki K, Fukamachi H, Komori K, Ohtake Y, Nonaka T, Sakamoto T, et al. Stroma-derived matrix metalloproteinase (MMP)-2 promotes membrane type 1-MMP-dependent tumor growth in mice. Cancer Res 2007;67:4311-9.

25. Cho YB, Lee WY, Song SY, Shin HJ, Yun SH, Chun HK. Matrix metalloproteinase- 9 activity is associated with poor prognosis in T3-T4 node-negative colorectal cancer. Hum Pathol 2007;38:160310.

26. Maurel J, Nadal C, Garcia-Albeniz X, Gallego R, Carcereny E, Almendro V, et al. Serum matrix metalloproteinase 7 levels identifies poor prognosis advanced colorectal cancer patients. Int J Cancer 2007;121:1066-71.

27. Curran S, Dundas SR, Buxton J, Leeman MF, Ramsay R, Murray GI. Matrix metalloproteinase/tissue inhibitors of matrix metalloproteinase phenotype identifies poor prognosis colorectal cancers. Clin Cancer Res 2004;10:8229-34. 